\title{
Aplikasi Peta Interaktif Berbasis Teknologi Augmented Reality Kawasan Pariwisata Pulau Bawean
}

\author{
Fakhrusy Luthfan Mahfuzh, Agung Budi Cahyono \\ Departemen Teknik Geomatika, Fakultas Teknik Sipil dan Perencanaan, Institut Teknologi Sepuluh \\ Nopember (ITS) \\ e-mail: agungbc@geodesy.its.ac.id
}

\begin{abstract}
Abstrak-Pulau Bawean merupakan salah satu kawasan pariwisata di Jawa Timur. Pulau Bawean terletak di Laut Jawa, sekitar 100 kilometer sebelah utara Kota Gresik. Kawasan Pariwisata Pulau Bawean masih sangat kurang dalam penyebaran informasi, jika dibandingkan dengan kawasan pariwisata lainnya. Dalam penelitian ini dilakukan sebuah pembuatan peta interaktif berbasis teknologi Augmented Reality kawasan pariwisata Pulau Bawean. Augmented Reality merupakan teknologi yang menggabungkan benda maya dua dimensi dan ataupun 3 dimensi lalu memproyeksikan bendabenda maya tersebut secara real time. Peta interaktif kawasan pariwisata Pulau Bawean berbasis teknologi Augmented Reality akan ditampilkan dalam sebuah bentuk aplikasi smartphone. Sehingga informasi dapat menyebar luas dan diperoleh secara mudah. Peta interaktif berbasis teknologi Augmented Reality kawasan pariwisata berhasil diimplementasikan pada device android. Dalam hasil uji coba pengguna dapat melihat visualisasi pariwisata Pulau Bawean menggunakan device android. Dalam aplikasi tersebut digunakan 5 marker peta kawasan pariwisata yang terdapat di Pulau Bawean yang kemudian jika discan salah satu marker tersebut akan menampilkan sebuah peta 3D dari kawasan pariwisata di Pulau Bawean. Aplikasi dapat digunakan sebagai media informasi yang dapat menyebarkan informasi pada smartphone dengan tampilan yang user friendly dan mudah digunakan sehingga dapat digunakan oleh masyarakat.
\end{abstract}

Kata Kunci-Augmented Reality, Marker, Peta 3 Dimensi, Pulau Bawean, User Friendly.

\section{PENDAHULUAN}

$\mathrm{P}$ ULAU Bawean merupakan salah satu kawasan wisata terbaik di Jawa Timur. Pulau Bawean adalah sebuah pulau yang terletak di Laut Jawa, sekitar 100 kilometer sebelah utara Gresik [1] . Di pulau ini terdapat banyak potensi dalam bidang pariwisata, dengan berbagai macam jenis wisata yang ditawarkan di pulau ini. Karena letaknya yang sangat jauh Pulau Bawean masih kurang dalam Infrastruktur dan penyebaran informasi juga masih sangat kurang di Pulau Bawean tersebut. Jika dibandingkan dengan kawasan pariwisata lainnya, kawasan wisata Pulau Bawean masih kurang terekspose oleh media informasi sehingga tidak banyak wisatawan yang mengetahui keberadaan dari pulau tersebut.

Peta kawasan pariwisata merupakan penyajian informasi media yang dapat menggambarkan lokasi dan wilayah dari suatu kawasan pariwisata. Dengan adanya sebuah peta para wisatawan dapat mengetahui keadaan dari wilayah tersebut. Dan dengan adanya sebuah peta dapat menjadi sebuah media pemasaran sebuah kawasan pariwisata, tetapi rata-rata sebuah kawasan pariwisata hanya mempunyai peta kawasan pariwisata yang sederhana bahkan tidak dapat menggambarkan keadaan dari wilayah tersebut.

Teknologi komputer merupakan solusi yang paling relevan. Karena kebanyakan pemasaran hanya berupa penyajian informasi media $2 \mathrm{D}$, karena itu pengembangan teknologi 3D dapat dilakukan. Selain itu teknik visualisasi 3D mempunyai nilai tambah dalam strategi pemasaran. karena merupakan solusi yang menarik bagi para pelaku bisnis yang dituntut untuk selalu kreatif [2]. Augmented Reality merupakan teknologi yang menggabungkan benda maya dua dimensi dan ataupun tiga dimensi ke dalam sebuah lingkungan nyata tiga dimensi lalu memproyeksikan bendabenda maya tersebut secara real-time. Benda-benda maya menampilkan informasi berupa label maupun obyek virtual yang hanya dapat dilihat dengan kamera handphone maupun dengan komputer. Sistem dalam augmented reality bekerja dengan menganalisa secara real-time obyek yang ditangkap dalam kamera [3].

Pada studi ini, diperlukan membuat sebuah Peta interaktif berbasis teknologi Augmented Reality kawasan pariwisata yang menghasilkan sebuah penerapan dari teknologi Augmented Reality yang dapat menampilkan objek virtual 3D kedalam lingkungan yang nyata. Jadi dengan melihat peta tersebut bisa menjadi sebuah acuan perencanaan pembangunan infrastruktur di Pulau Bawean dan para wisatawan dapat mengetahui keadaan dari kawasan pariwisata tersebut dan dapat mengekspose kawasan pariwisata Pulau Bawean, sehingga masyarakat dapat mengetahui keberadaan dari kawasan pariwisata Pulau Bawean.

\section{URAIAN PENELITIAN}

\section{A. Lokasi Penelitian}

Lokasi penelitian studi ini dilakukan di wilayah kawasan pariwisata Pulau Bawean, Kabupaten Gresik, Jawa Timur. Survey Lapangan akan lakukan di bulan Februari 2017 dan Maret 2017. Adapun zona zona wilayah yang akan dijadikan sebagai wilayah penelitian sebagai berikut : 

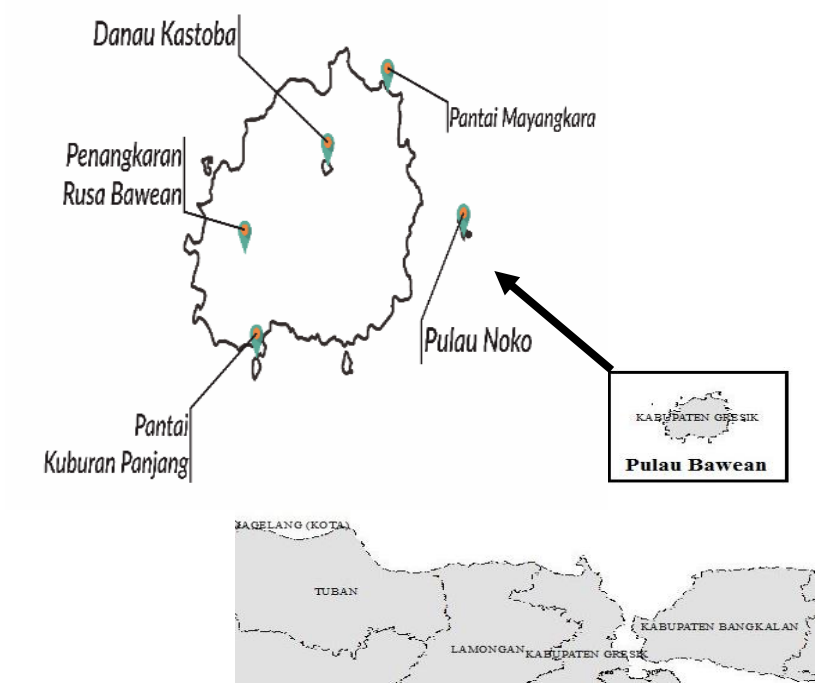

Gambar 1. Zona Wilayah Penelitian

Tabel 1.

Zona Wilayah Penelitian

\begin{tabular}{cll}
\hline \hline NO & Name & Ciri Khas Pariwisata \\
\hline 1 & Pulau Noko & Pasir Putih \\
& Pantai Kuburan & Makam Panjang \\
2 & Panjang & Pohon tumbang \\
3 & Pantai Mayangkara & Danau Diantara Bukit \\
4 & Danau Kastoba & Rusa Bawean \\
& Penangkaran Rusa & \\
\hline \hline
\end{tabular}

\section{B. Data dan Peralatan}

\section{1) Data}

Data yang dibutuhkan dalam Studi ini adalah :

1. Peta kawasan pariwisata Pulau Bawean

2. Peta pariwisata 3 Dimensi

2) Peralatan

Peralatan yang dibutuhkan dalam Studi ini adalah:

\section{Perangkat Keras (Hardware)}

- Desktop PC Core i7-2630QM 2.0 GHz, Memory 4.0 GB RAM, VGA Nvidia GeForce GT 5402 GB, Hard Drive 1.0 TB,

\section{Perangkat Lunak (Software)}

- Sistem Operasi Windows 10

- DirectX 11

- Unity3D Engine 5.5

- $\quad$ Vuforia SDK versi 2.6.7

\section{Tahapan Pengolahan Data}

Tahapan pengolahan data pada penelitian ini adalah sebagai berikut:

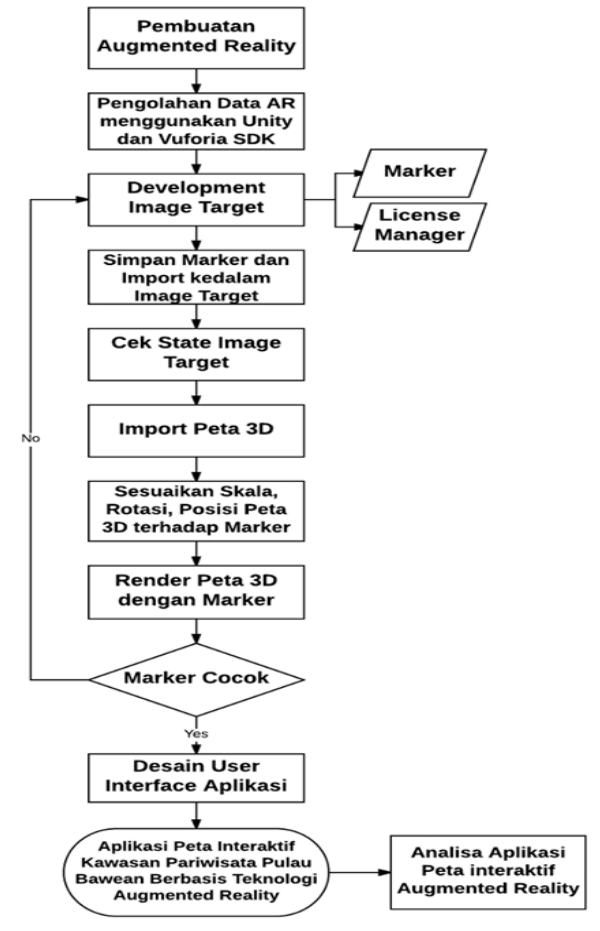

Gambar 2. Pengolahan Augmented Reality

1. Pembuatan Augmented Reality

Menggabungkan sebuah benda maya dengan dunia real kemudian memproyeksikannya secara real time adalah sebuah teknologi Augmented Reality. Dalam pembuatan AR membutuhkan sebuah marker dan objek virtual. Dalam penelitian ini menggunakan sebuah peta kawasan pariwisata sebagai marker dan objek virtual yang berupa peta 3 dimensi kawasan pariwasata. Kita menggabungkan antara marker dan objek virtual menggunakan software unity dan vuforia agar dapat dijadikan sebuah Augmented Reality

2. Development Image Target

Dalam melakukan pembuatan AR kita perlu menggunakan Vuforia untuk membangun sebuah Image Target. Daftarkan marker kedalam dunia AR dengan cek pattern marker dengan vuforia, maka akan terlihat bagaimana maeker terbut dapat digunakan atau tidak yang akan ditunjukkan melalui rating.

3. Cek State Image Target

Import marker yang sudah didaftarkan kedalam dunia AR ke Image Target. Kemudian setelah itu import objek virtual yang ingin diproyeksikan yaitu peta 3 dimensi kawasan pariwisata. Untuk dapat mengimport data peta 3D harus di eksport ke format (.Fbx). Sesuaikan skala, rotasi dan posisi dari objek terhadap marker agar sesuai dengan ukuran marker.

4. Render peta 3 Dimensi dengan Marker

Lakukan proses render peta 3D dengan marker agar dapat menjadi sebuah aplikasi Augmented Reality.

5. Desain User Interface

Tahap akhir dalam penelitian ini adalah pembuatan aplikasi Augmented Reality, oleh karena itu kita membutuhkan User Interface agar aplikasi dapat diakses oleh pengguna dengan mudah dan user friendly. 


\section{HASIL DAN PEMBAHASAN}

\section{A. Hasil}

\section{1) Marker}

Marker adalah hal yang paling utama dalam pembuatan Augmented Reality. Pada penelitian kali ini marker menggunakan peta kawasan pariwisata. Berikut marker yang digunakan pada penelitian kali ini.

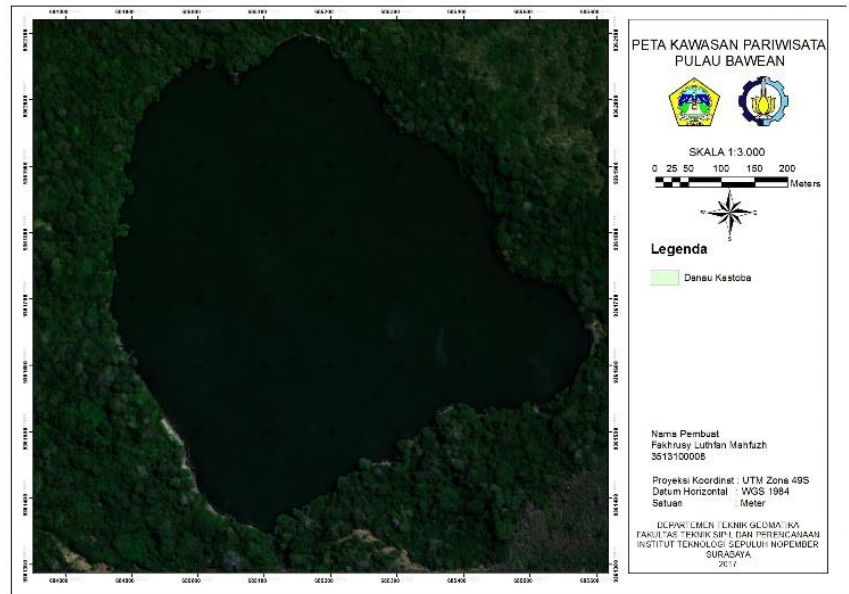

Gambar 3a. Marker Kawasan Pariwisata Danau Kastoba

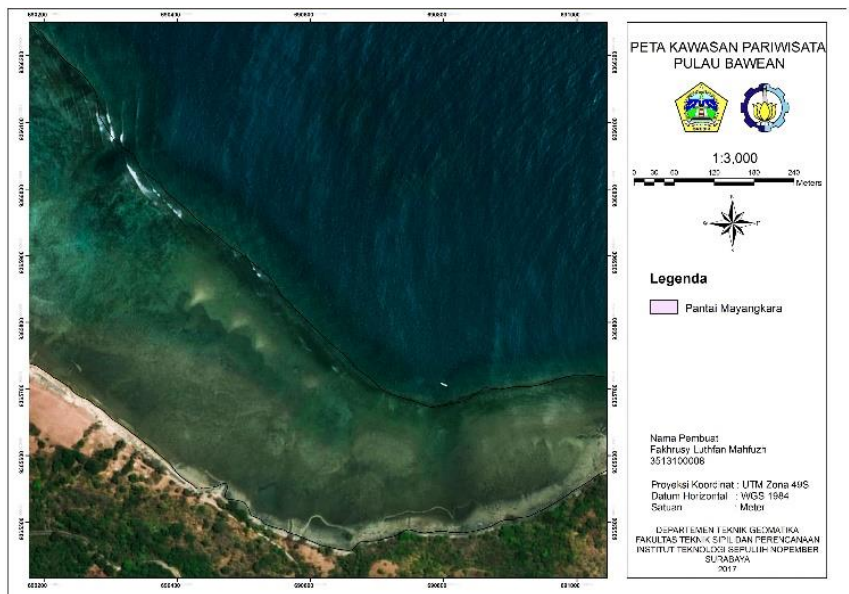

Gambar 3b. Marker Kawasan Pariwisa Pantai Mayangkara
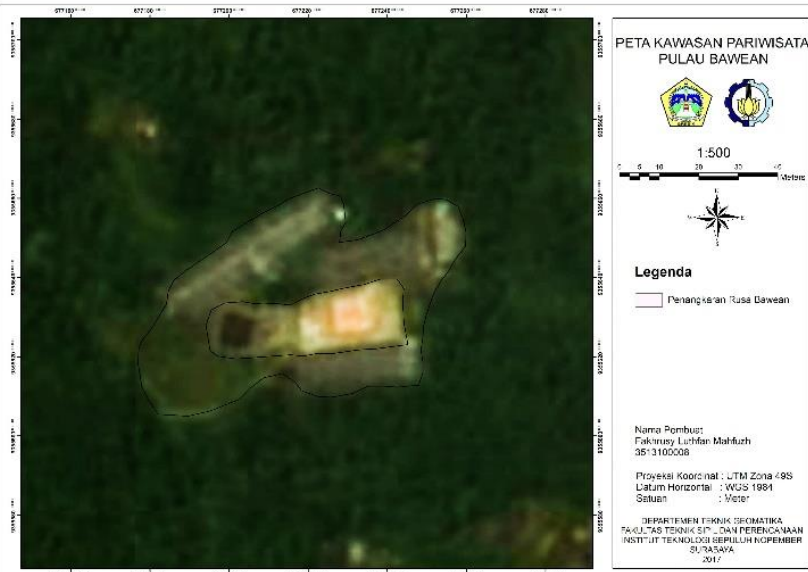

Gambar 3c. Marker Kawasan Pariwisata Penangkaran Rusa

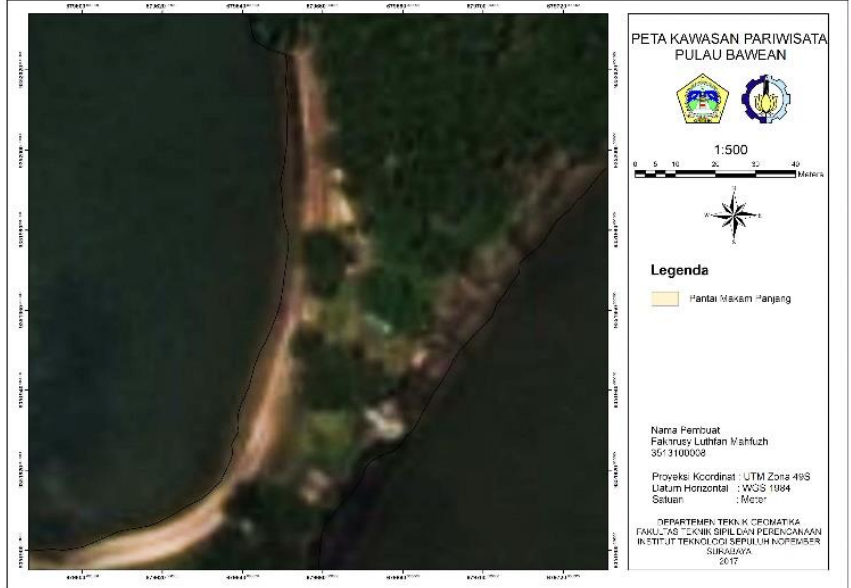

Gambar 3d. Marker Kawasan Pariwisata Pantai Kuburan Panjang
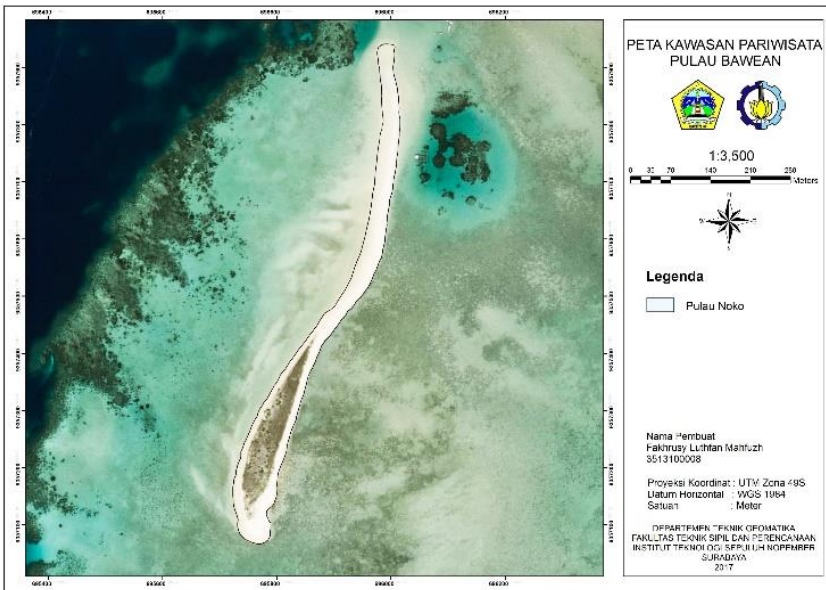

Gambar 3e. Marker Kawasan Pariwisata Pulau Noko

Image marker tersebut yang akan digunakan dalam pembuatan Augmented Reality. Kamera akan scan salah satu dari marker kawasan pariwisata Pulau Bawean yang kemudian akan dihasilkan proyeksi peta 3D kawasan pariwisata Pulau Bawean.

\section{Development Image Target}

Dalam proses pembuatan Augmented Reality yang pertama dilakukan adalah develop image target. Untuk membangun sebuah marker kita harus menemukan pattern dari image marker tersebut. Pattern adalah string image target hasil tangkapan kamera AR.
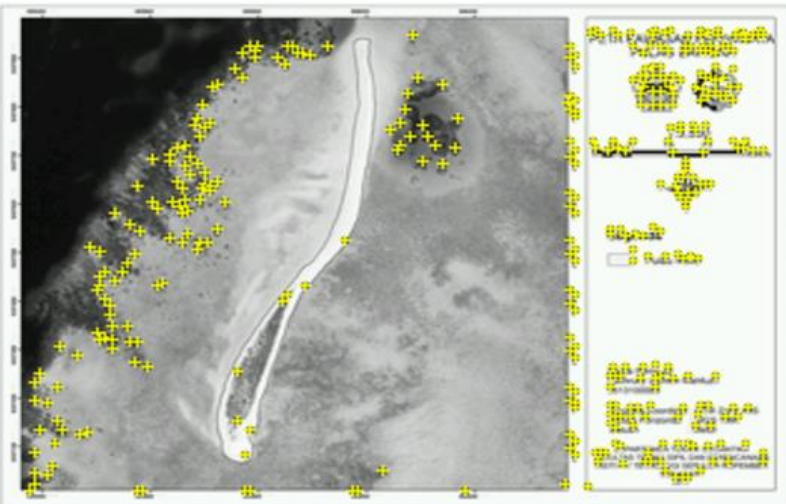

Gambar 4. Pattern Image Marker 
Setelah menemukan pattern dari image marker tersebut, kemudian muncul rating dari tiap marker yang sudah didapatkan pattern dari image marker peta kawasan pariwisata Pulau Bawean.

\begin{tabular}{|c|c|c|c|c|}
\hline Target Name & Type & Rating & Statusv & Date Modified \\
\hline Pulau_Noko & Single Image & 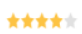 & Active & May 08, $201704: 42$ \\
\hline Mayangkara & Single Image & 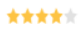 & Active & May 08, 2017 04:38 \\
\hline PenangkaranRusa & Single Image & 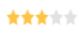 & Active & May 08, 2017 04:35 \\
\hline makampanjang & Single Image & 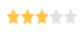 & Active & May $08,201704: 29$ \\
\hline Danau_Kastoba & Single Image & 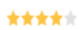 & Active & May 08, 2017 04:25 \\
\hline
\end{tabular}

Gambar 5. Rating Marker didalam Dunia AR

\section{Pembuatan Augmented Reality}

Setelah itu lakukan pengolahan data Augmented Reality menggunakan software Unity. Masukkan AR camera dan Image target yang terdapat dalam library unity. Kemudian kita menggabungkan antara marker dan peta 3D kawasan pariwisata.

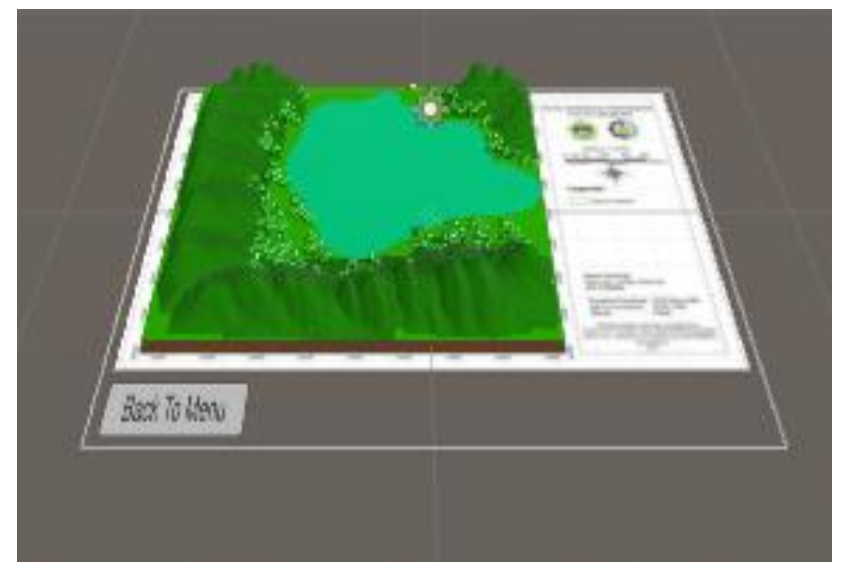

Gambar 6a. Image Marker dengan Peta 3D Danau Kastoba

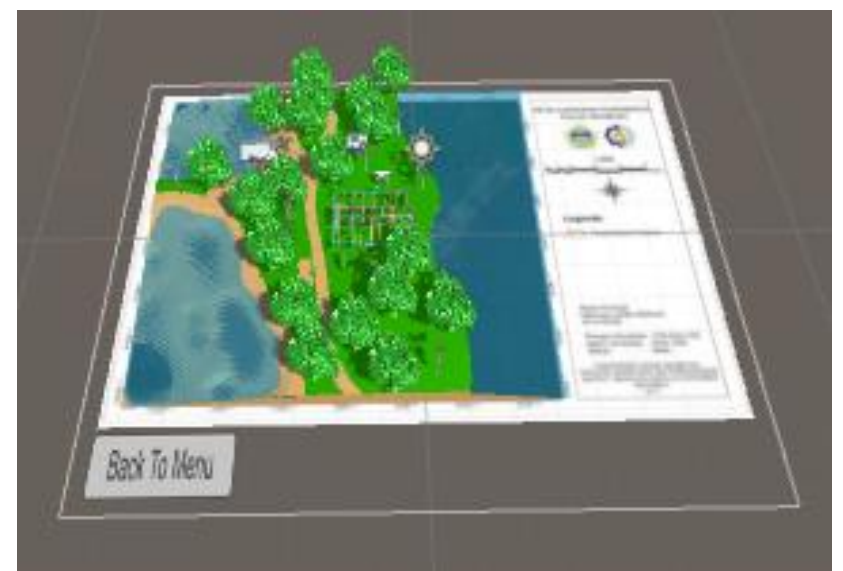

Gambar 6b. Image Marker dengan Peta 3D Pantai Kuburan Panjang

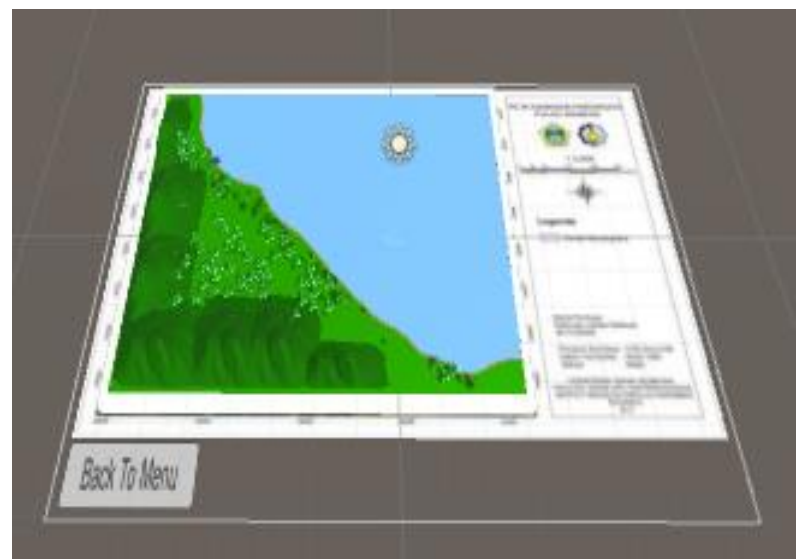

Gambar 6c. Image Marker dengan Peta 3D Pantai Mayangkara

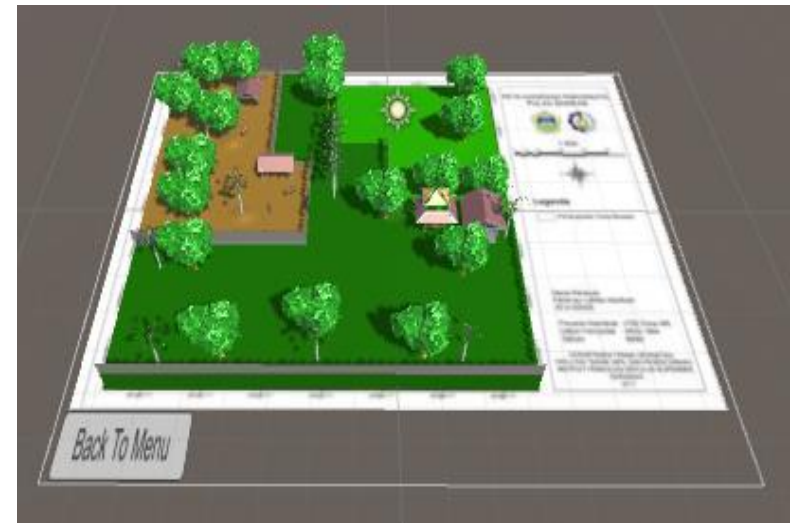

Gambar 6d. Image Marker dengan Peta 3D Penangkaran Rusa

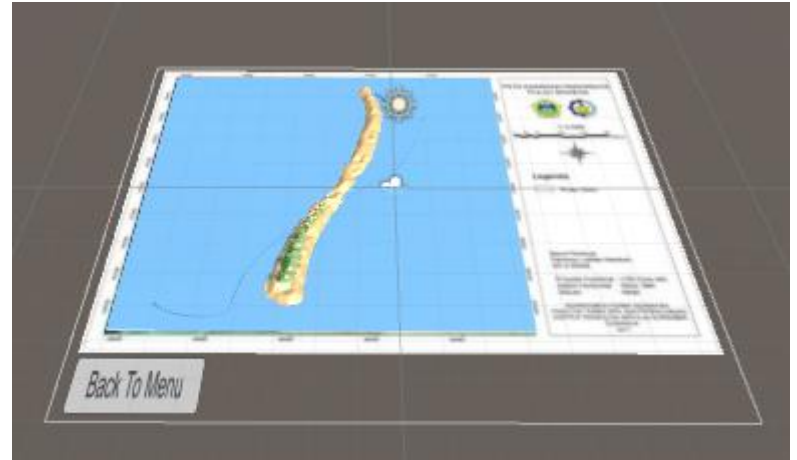

Gambar 6e Image Marker dengan Peta 3D Pulau Noko

Setelah penggabungan antara image marker dan peta 3D selesai dilakukan. Perlu ditambahkan material kedalam peta 3D tersebut karena ketika import 3D ke software unity, peta 3D tidak sempurna. Ada beberapa material yang tidak support untuk di render di software unity. Setelah penambahan material kemudian render image marker dengan peta 3D agar menjadi Augmented Reality.

4. Implementasi Aplikasi

a)

Tampilan Menu Awal

Pada tahap ini pembuatan aplikasi membutuhkan sebuah desain interface agar pengguna dapat dengan mudah menggunakan aplikasi tersebut. Pada halaman pertama terdapat tampilan halaman menu yang ditampilkan sebagai berikut 


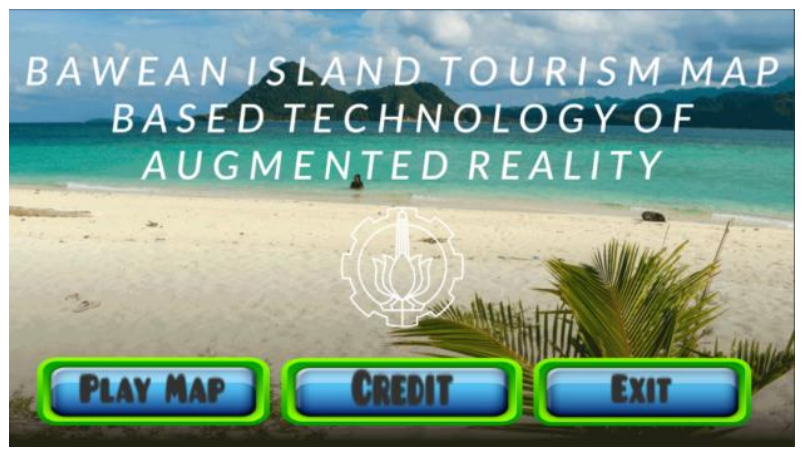

Gambar 7. User Interface Halaman Menu

Setelah masuk halaman menu terdapat 3 button yang dapat ditampilkan. Kemudian hasil yang ditampilkan ketika memilih button credit adalah sebagaiberikut.

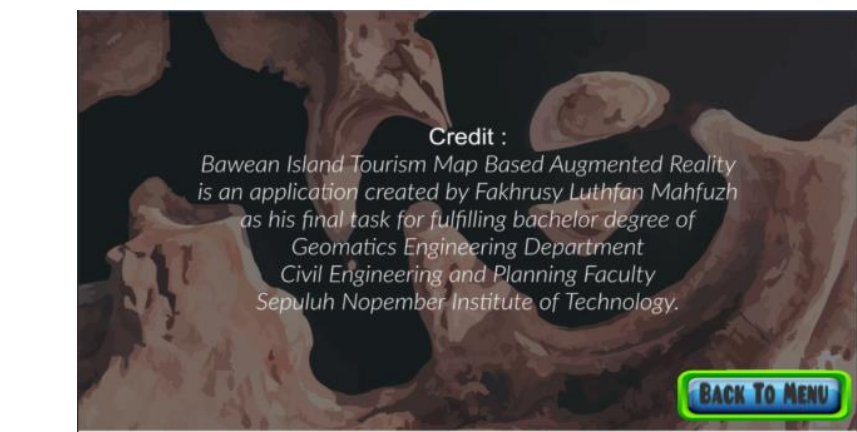

Gambar 8. User Interface Halaman Credit

c) Tampilan Menu Play

Untuk memulai aplikasi tersebut pilih button Play Map kemudian yang akan menampilkan sebuah peta yang menunjukkan lokasi dari pasriwisata di Pulau Bawean.

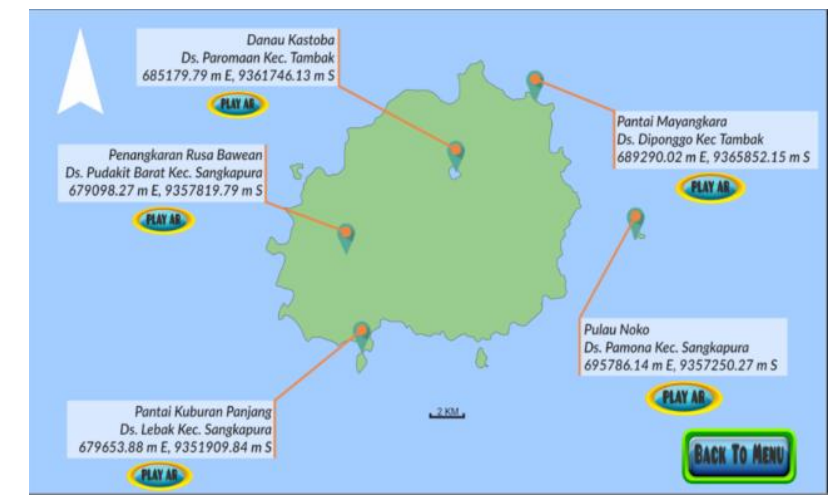

Gambar 9. User Interface Halaman Play Map

d)

Aplikasi Augmented Reality

Setelah masuk ke menu Play Map terdapat 5 buah kawasana pariwisata dan terdapat button Play AR, ketika button tersebut akan langsung masuk ke dunia AR. Tampilan yang dihasilkan oleh aplikasi Augmented Reality adalah sebuah camera Setelah muncul tampilan kamera kemudian scan marker yang sesuai dengan kawasan pariwisata yang dipilih untuk memulai Augmented Reality.

\section{Uji Coba Aplikasi}

Pengujian aplikasi ini dilakukan terhadap system android. Tujuan penguji coba aplikasi ini adalah untuk mengetahui fungsionalis dari aplikasi ini dapat berfungsi [4].

Langkah langkah dalam ujicoba aplikasi ini adalah sebagai berikut.

i. Build aplikasi Augmented Reality ke platform android dan menghasilkan sebuah apk.

ii. Unduh apk lalu install ke system android.

iii. Jalankan aplikasi tersebut di android.

iv. Uji beberapa tombol yang terdapat di halaman User Interface.

v. Pada halaman AR, uji kamera AR dengan mengrahkan ke marker.

vi. Amati apakah aplikasi dapat mendeteksi pola marker dan dapat menampilkan objek 3D.

Tabel 2.

Tabel Uji Aplikasi

\begin{tabular}{ccc}
\hline \hline NO & Komponen Pengujian & Hasil Pengujian \\
\hline 1 & Membuka Aplikasi & Berhasil \\
2 & Membuka Tampilan Menu Awal & Berhasil \\
3 & Button Exit & Berfungsi \\
4 & Button Credit & Berfungsi \\
5 & Button Play Map & Berfungsi \\
6 & Membuka Tampilan Credit & Berhasil \\
7 & Membuka Tampilan Play Map & Berhasil \\
8 & Button Play AR & Berfungsi \\
9 & Button Back To Menu & Berfungsi \\
10 & Membuka Menu AR & Berhasil \\
11 & Kamera AR & Berfungsi \\
12 & Membaca Marker & Berhasil \\
13 & Memproyeksikan Peta 3D & Berhasil \\
14 & Lean Touch Zoom & Tidak Berfungsi \\
15 & Button Back To Menu & Berfungsi \\
\hline \hline
\end{tabular}

\section{KESIMPULAN}

Kesimpulan dari penelitian ini adalah:

1. Telah berhasil dibuat sebuah aplikasi peta interaktif berbasis teknologi Augmented Reality kawasan pariwisata Pulau Bawean. Aplikasi tersebut diimpelementasikan dalam device android. Dengan Aplikasi tersebut dapat menampilkan visualisasi keadaan dari pariwisata di Pulau Bawean.

2. Berdasarkan hasil Uji Coba, aplikasi dapat berfungsi dengan baik. Perbandingan antara kondisi real dan visualisasi 3D yang telah dilakukan terdapat beberapa perbedaan, hal itu disebabkan oleh beberapa faktor seperti pencahayaan saat pengambilan data dokumentasi dan dalam pembuatan objek 3D pariwisata tersebut.

3. Aplikasi peta interaktif berbasis teknologi Augmented Reality bertujuan untuk memberikan informasi kepada masyarakat umum kondisi kawasan pariwisata di Pulau Bawean, oleh karena 
itu diakses menggunakan android dengan tampilan yang user friendly dan mudah digunakan.

Saran dari penelitian ini adalah:

1. Perlu menggunakan sumber daya hardware yang mempunyai spesifikasi tinggi karena membutuhkan memory RAM diatas 4 GB agar tidak mengalami proses yang lama.

2. Dapat diimplementasikan teknologi augmented reality pada platform lain yang memberikan support seperti pada iPhone, Blackberry dan Windows Phone.

3. Diperlukan penelitian lebih lanjut sperti penambahan informasi yang lebih detail dan pengembangan aplikasi yang lebih baik agar dapat disebar ke masyarakat luas.

\section{DAFTAR PUSTAKA}

[1] Soedjijono, "Pulau Bawean," 2002. [Online]. Available: url:https://id.wikipedia.org/wiki/Pulau_Bawean.

[2] N. . Asfari, U., Setiawan, B., Sani, "Pembuatan Aplikasi Tata Ruang Tiga Dimensi Gedung Serba Guna Menggunakan Teknologi Virtual Reality," ITS, 2012.

[3] B. Azuma, R., Baillot, Y., Behringer, R., Feiner, S., Julier, S., and MacIntyre, "Recent advances in augmented reality," IEEE, vol. 21, no. 6 , pp. $34-47,2001$

[4] N. Jazilah, "Aplikasi Pembelajaran Berbasis Augmented Reality pada Buku Panduan Wudhu Untuk Anak.," Universitas Islam Negeri Malang, 2016. 